\begin{tabular}{|c|l|}
\hline Title & The Distribution of Crustose Corallines in Eastern Hokkaido and the Biogeographic Relationships of the Flora \\
\hline Author(s) & A DEY, Walter H.; MA SA KI, Tomitaro; A KIOKA, Hidetsugu \\
\hline Citation & 北海道大學水産學部研究彙報, 26(4), 303-313 \\
\hline Issue Date & 1976-03 \\
\hline Doc URL & http://hdl.handle.net/2115/23569 \\
\hline Type & bulletin (article) \\
\hline File Information & 26(4)_P303-313.pdf \\
\hline
\end{tabular}

Instructions for use 
Bull. Fac. Fish. Hokkaido Univ.

26(4), 303-313. 1976.

\title{
The Distribution of Crustose Corallines in Eastern Hokkaido and the Biogeographic Relationships of the Flora*
}

\author{
Walter H. Ader**, Tomitaro Masaki*** and Hidetsugu Akjoks****
}

\section{Introduction}

Crustose coralline red algae are among the most ubiquitous of marine benthic algae, occurring on hard substrate in the sublittoral photic zone from the tropics to polar regions. They are slow growing perennials, and it has been demonstrated in the North Atlantic that coralline species show rather well defined geographic and depth distribution patterns (summarized in Adey and Adey')). It has been known for several decades that some subarctic species of corallines are common to both Hokkaido and the North Atlantic (Masaki $\left.{ }^{2}\right)$ ). The present study was begun in the summer of 1972 with the intention of examining the relationship of the Hokkaido flora with that of the North Atlantic. The ecological results are presented here. A detailed biosystematic study of the species involved is being published separately (Masaki, Akioka and Adey, in prep. $\left.{ }^{3}\right)$.

The field of marine-biogeography, as summarized by Hedgepeth' ${ }^{4)}$ and Ekman, 5) has developed extensively during the 20th century. Generally, water temperature and geographical isolation have been considered to be the chief factors determining the development of areally distinct biotas or biogeographical provinces. However, Rotramel $\left.{ }^{6}\right)$ stressed the need for considering the size of an area existing under a particular climatic regime, while earlier Stehli and Wells) had suggested that the higher rates of coral evolution and diversity in the Pacific as opposed to the Caribbean were the result of "a strong area effect". In an attempt to establish a physical basis for the biogeographic distribution of shallow water benthic algae, Adey (in ms.) has developed a graphic representation of the total amount of coastline, within geographically contiguous areas, available at any combination of summer and winter mean temperatures. The North Pacific and North Atlantic sections of that coastline-temperature field are shown in figure 1. The temperature-geographic relationships shown in figure 1 are also approximately the same as those that existed during the ten million years of the Pliocene, just prior to the intensive northern hemisphere Pleistocene glaciations. It would have been

* This study uas supported by the Japan-U.S. Cooperative Science Program. Contribution No. 12 from the Usujiri Fisheries Laboratory, Faculty of Fisheries, Hokkaido

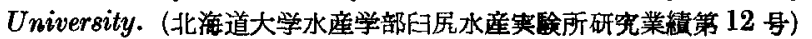

** Division of Paleobotany, Smithsonian Institution, Washington, D.C., 20560 U.S.A. (スミソニアン研究所古植物学部門)

*** Laboratory of Marine Botany, Faculty of Fisheries, Hokkaido University, Hakodate. (北海道大学水産学部水産植物学楎座)

**** Laboratory of Biology, Hokkaido Kyoiku University, Hakodate. (北海道教育大学函館分枚生物学教空) 
Bull. Fac. Fish. Hokkaido Univ. 26(4). 1976.

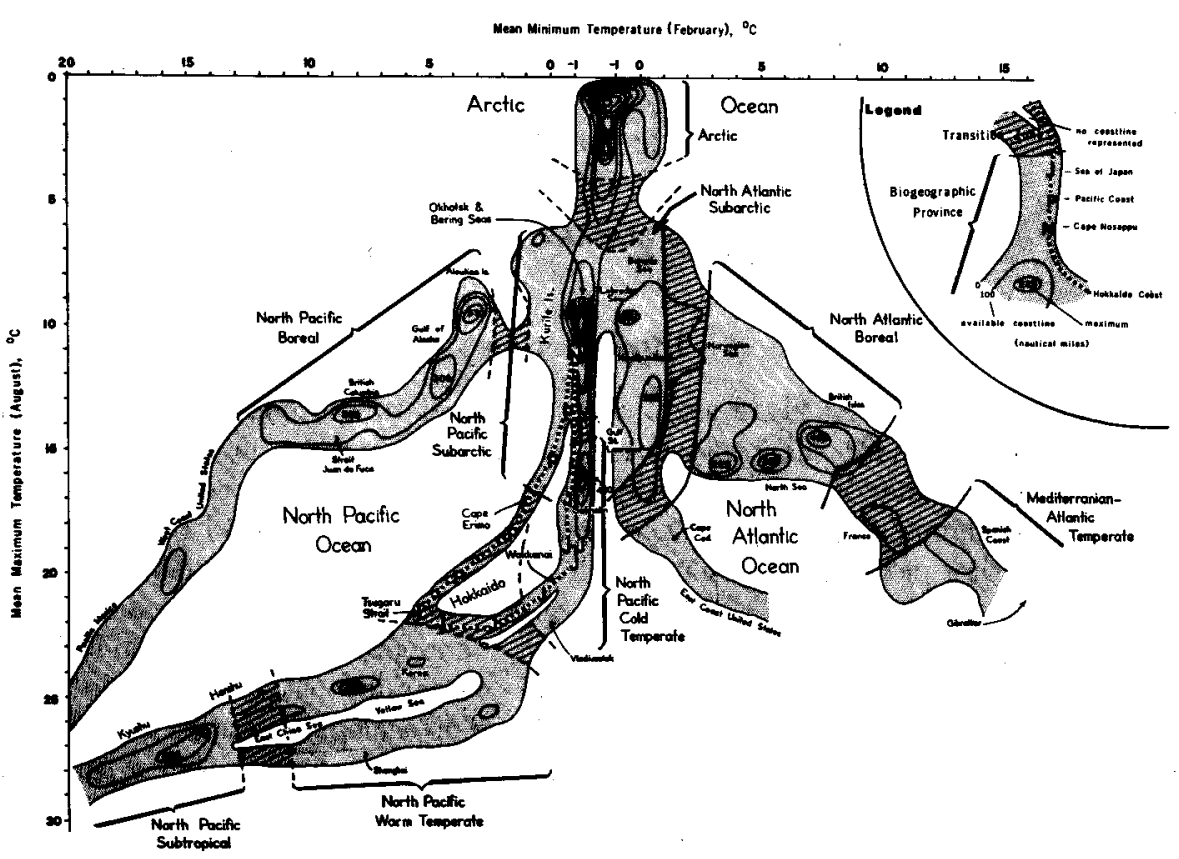

Fig. 1. Northern, shallow water benthic-marine biogeographic provinces as based on coastline length (in $1^{\circ} \mathrm{C}$ square units) as a function of mean maximum (August) and mean minimum (February) temperatures. The Hokkaido coastline sections of the original working diagram (in 60 nautical mile intervals) from Cape Nosappu (N) to Tsugaru Strait $(\mathbf{T})$ by way of the Pacific Coast $(\mathrm{P})$ and the Japan Sea Coast $(J)$ are shown; other coast details have been omitted.

largely during that interval that the major biogeographic patterns for slowly evolving groups, such as the corallines, would have been established. Theoretically, biogeographic provinces can be located where large amounts of contiguous coastline occur with similar temperature patterns. In figure 1, the province boundaries indicated with solid lines are those previously established, in relation to crustose corallines (Adey and Adey, l. c.), or developed in this paper. The dashed boundary lines are theoretical, based on the diagram itself.

As can be seen in figure 1, Hokkaido falls within a rather marked zone of temperature change. The Pacific coast of Hokkaido represents only $6 \%$ of the total coastline length of the northeastern Pacific Ocean, as measured from the Bering Sea to the Philippine Islands. However, approximately $35 \%$ of the total temperature change found between the arctic and the tropics occurs on this coast. This results largely from the confluence of the cold Oyashio current with the warm Tsugaru, Soya and Kuroshio currents (Fig. 2). As compared with a similar current pattern in the western North Atlantic, the actual temperaturegeographic patterns are also further complicated by the position of Hokkaido in an island arc system, the result of a basic geologic difference between a complex "Pacific type" subduction coast as opposed to a rather simple "Atlantic type" 
rifting coast. Thus, this relatively small island appears to lie at the meeting points of three shallow marine biogeographic provinces, as based on figure 1. The sea surface temperatures along the eastern coast of Hokkaido, from Akkeshi to Cape Nossapu on the Nemuro Peninsula, range from nearly 0 to $-1^{\circ} \mathrm{C}$ in winter to about 12 to $15^{\circ} \mathrm{C}$ in summer. This places it at the southern end of the very large Pacific subarctic province. However, in the Tsugaru Strait, only $500 \mathrm{~km}$ (270 nautical miles) distant to the southwest, the winter-summer sea temperature ranges from 5 or $6^{\circ} \mathrm{C}$ to $20-23^{\circ} \mathrm{C}$. These are close to the temperature patterns found in a large part of the Sea of Japan, the Yellow Sea and the northern East China Sea, here grouped as the North Pacific warm temperate province.

The Nemuro Peninsula in the east is especially interesting biogeographically and represents a sharp division in the coastline profile diagrammed in figure 1. As has been stated above, the southern side of the peninsula is dominated by the cold Oyashio, and lies within the subarotic province. However, the coast extending to the northwest of the peninsula is warmed by an arm of the current passing through the Soya Strait in summer, and sometimes sea temperatures reach levels of $20^{\circ} \mathrm{C}$ or greater. In the late winter, the influence of this current diminishes as northerly winds off the Okhotsk Sea drive pack ice onto the shore, and sea temperatures plunge to below zero. This wide temperature range is characteristic of a rather large coastal area centered on the island of Sakhalin between the southern Okhotsk Sea and the northern Sea of Japan. We have designated this marine area the North Pacific cold temperate province. The Nemuro Peninsula forms a rather narrow geographic boundary between a subarctic flora to the southeast and a cold temperate flora to the northwest.

\section{Materials and Methods}

The surface sea water temperature data used in the study were obtained from a variety of sources. The temperature-area diagram of figure 1 was derived largely from the U.S. Naval Hydrographic Office SP-123, Monthly Charts of mean minimum and maximum sea surface temperatures of the North Pacific Ocean (1969), with modifications in the North Atlantic made according to a variety of local oceanographic studies. Coastline length was measured and temperatures plotted in 60 nautical mile units. The coastline length contouring shown in figure 1 is based on the amount of coastline occurring within $1^{\circ} \mathrm{C}$ squares. The "extra" length of fjord coastline was not included, as this is a relatively recent (Pleistocene) feature.

Coastal temperatures in Hokkaido posed a special problem. Figure 3 shows the August mean temperatures taken from three different sources. Generally there is fair agreement in the temperature maxima data. For the coast between Erimo to Nosappu, fisheries temperature data for August 1967 from $20 \mathrm{~km}$ offshore are similar to temperatures that we took while collecting in August-September 1972. However, these temperatures are several degrees colder than the four year mean taken at the algal cultivation stations at Shiranuka (just west of Kushiro) and Akkeshi. In the two-day period during which we occupied two stations at 
Bull. Fac. Fish. Hokkaido Univ, 26(4), 1976.

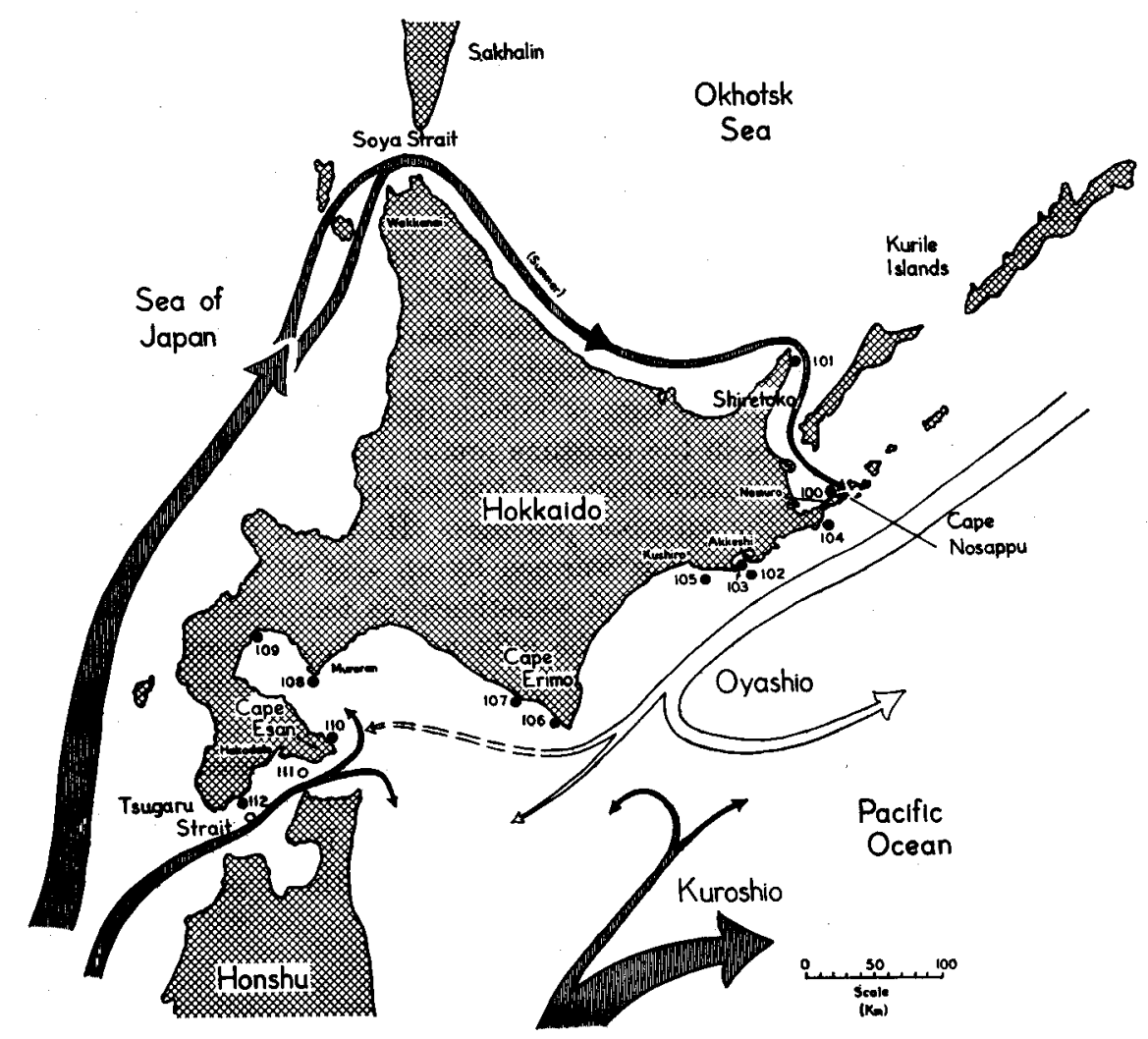

Fig. 2. Map of Hokkaido showing transect stations occupied during the course of this study and the positions of the major ocean currents. $\bullet$, depth transect station taken by SCUBA; o, dredge complement station taken from "Ushio Maru".

Akkeshi Bay, one near the algal cultivation station just east of the Marine Laboratory, the other at Daikoku-Shima at the mouth of the Bay (station 102), the surface temperature in the bay was $18^{\circ} \mathrm{C}$, while at Daikoku-Shima it was only $11^{\circ} \mathrm{C}$. This suggests that the summer temperatures at the algal culture stations in this area are several degrees warmer than those along the outer coast. In figure 1, we have used a mean of the three data sources shown in figure 3 .

On the east coast, in the areas dominated by the effect of the cold offshore Oyashio (Fig. 2), there appears to be only a slight shallow water temperature gradient within the depth range of our stations. The temperatures taken while diving in the summer of 1972 ranged from $11-14^{\circ} \mathrm{C}$ on the surface, to $11-13^{\circ} \mathrm{C}$ at 20-30 meters depth. The bight between Shiretoko and Nemuro is similar though warmer in the summer; we measured $15-18^{\circ} \mathrm{C}$ at the surface, and a single reading at 30 meters, taken by remote sensor, registered a temperature drop of only $2^{\circ} \mathrm{C}$. The north coast from Wakkanai to Shiretoko, as reported in August of 
1967 in the Fisheries Bulletin (l. c.), shows a similar pattern, an approximate $2^{\circ} \mathrm{C}$ decrease at depth from surface temperatures of $15-16^{\circ} \mathrm{C}$. This suggests that in summer the currents are considerably more important than insolation warming in determining coastal temperatures. The high means $\left(17-21^{\circ} \mathrm{C}\right)$ reported at the algal culture stations on the shore from Wakkanai to Nemuro probably reflect the additional effects of surface warming in calm weather.

In the south, a relatively large warm current penetrates through the Tsugaru Strait from the Sea of Japan, and mixes with the Oyashio in an irregular fashion from Cape Esan to Cape Erimo. All of our stations in this area showed a marked thermocline, with summer temperatures of $16-20.5^{\circ} \mathrm{C}$ at the surface falling to $13-$ $15^{\circ} \mathrm{C}$ at 20 meters. Probably much of this is due to surface insolation in a relatively stagnant water mass being underridden by the cold current from the northeast. Temperatures taken at a depth of 60 meters, near shore at the eastern end of the Tsugaru Strait, varied from 16.8 to $22.4^{\circ} \mathrm{C}$, suggesting that at this depth the cold current actually penetrates irregularly into the mouth of the strait.

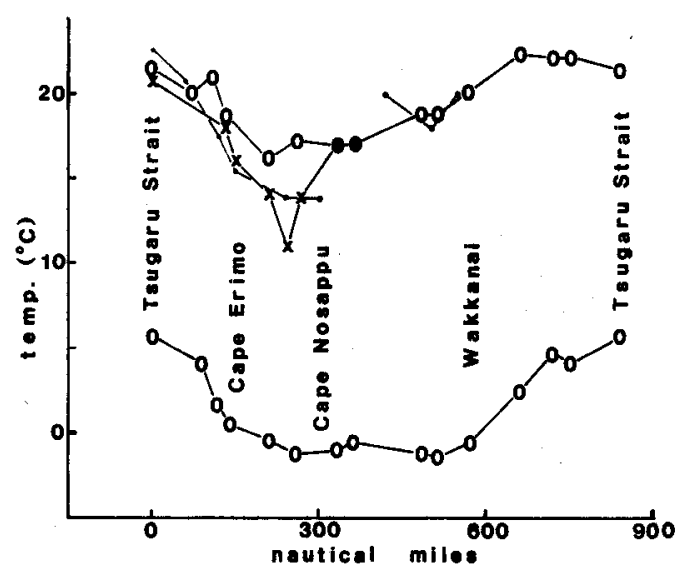

Fig. 3. Winter (bottom) and summer (top) mean sea surface temperatures (August, February) on the Hokkaido Coast. 0, algae culture stations; $X$, Fisheries research vessels, 1967; •, our data August-September, 1972.

The stations shown in figure 2 were occupied during August and September of 1972. The collections were taken by SCUBA diving in standard depth zones: 0-3, 3-9, 9-15, 15-21, 21-28 meters below mean low water. In the stations from Cape Erimo eastward, no collections were made deeper than 30 meters, which was found to be either the limit of rock substrate or, due to high turbidity, near the coastal photic limit. The photic limit in the Tsugaru Strait was greater than 30 meters, and there we were able to accomplish some dredging to 60 meters.

Within each depth zone, collections were taken with no effort made to identify species. However, we did try to include a representative size range of 
Bull. Fac. Fish. Hokkaido Univ. 26(4), 1976.

the substrate found at each site. Bedrock was collected by prying with a pinchbar, but because of the relative difficulty of removing such substrate, it may not be fairly represented in some cases. Adey ${ }^{8}$ ) has discussed the importance of substrate size relative to the abundance of coralline species.

Collected plants were kept alive in buckets and returned to sea water tanks at various shore facilities. Each collection was first studied alive and fragments selected for preparation for microtome sectioning. The 279 plants sectioned form the anatomic-morphologic base for the systematic work soon to be published. The remaining material, comprising nearly 1000 specimens of coralline coated rock and mollusk shell, was dried, and the area occupied by coralline crusts measured and recorded for each species. From these data, abundances of each species relative to the total coralline cover were calculated. These data, relative to depth and location, are presented in figure 4 .

\section{Results}

The distribution of the crustose coralline species along the southeast coast of Hokkaido, from the northeastern point of the Shiretoko Peninsula, to the northwestern side of the Tsugaru Strait, is shown in figure 4. The depth range given generally covers the total extent of crustose coralline development, except in the Tsugaru Strait where they extend to over 60 meters.

Three main species groupings have emerged (Fig. 4) and these are closely associated with the major temperature-area provinces that have already been discussed. The "subarctic" designation is applied only to those species also found in the subarctic of the North Atlantic, with the exception of one species. The one exception, Lithothamnium "pac-lem." is discussed below. No other species that are known to occur in the North Pacific subarctic (Bering Sea) were found in Hokkaido.

The cold temperate group consists of two major species, Hydrolithon sp. and Lithothamnium "23". These plants are dominant in northern Hokkaido, an area that shares temperature characteristics with much of the large Okhotsk Sea, Sakhalin, and northern Sea of Japan (Fig. 1). The genus Lithothamnium is widely distributed in the northern hemisphere and tropics, though it tends to occur in deeper water in warmer seas $\left(\right.$ Adey $\left.^{9}\right)$ ). Hydrolithon, on the other hand, is largely a tropical genus. While it has not been reported from Atlantic temperate to boreal areas (nor a subarctic to arctic area in any ocean), Dawson ${ }^{10}$ ) did find two species in the subtropical to temperate Pacific Mexico, and one of those extends into the boreal of the west coast of North America (Mason ${ }^{11)}$, as Lithophyllum decipiens).

The major elements of the apparent warm temperate group, Lithophyllum yessoense and Neogoniolithon sp., dominate the coralline flora from Tsugaru Strait to Point Erimo. The genus Lithophyllum generally characterizes temperate to subtropical seas, though one boreal species is known (North Atlantic-Lithophyllum orbiculatum, Adey and Adey, l.c.). The genus Neogoniolithon is one of the dominant tropical genera, and no representatives are known from arctic to boreal 
ADEY et al.: Crustose corallines in eastern Hokkaido
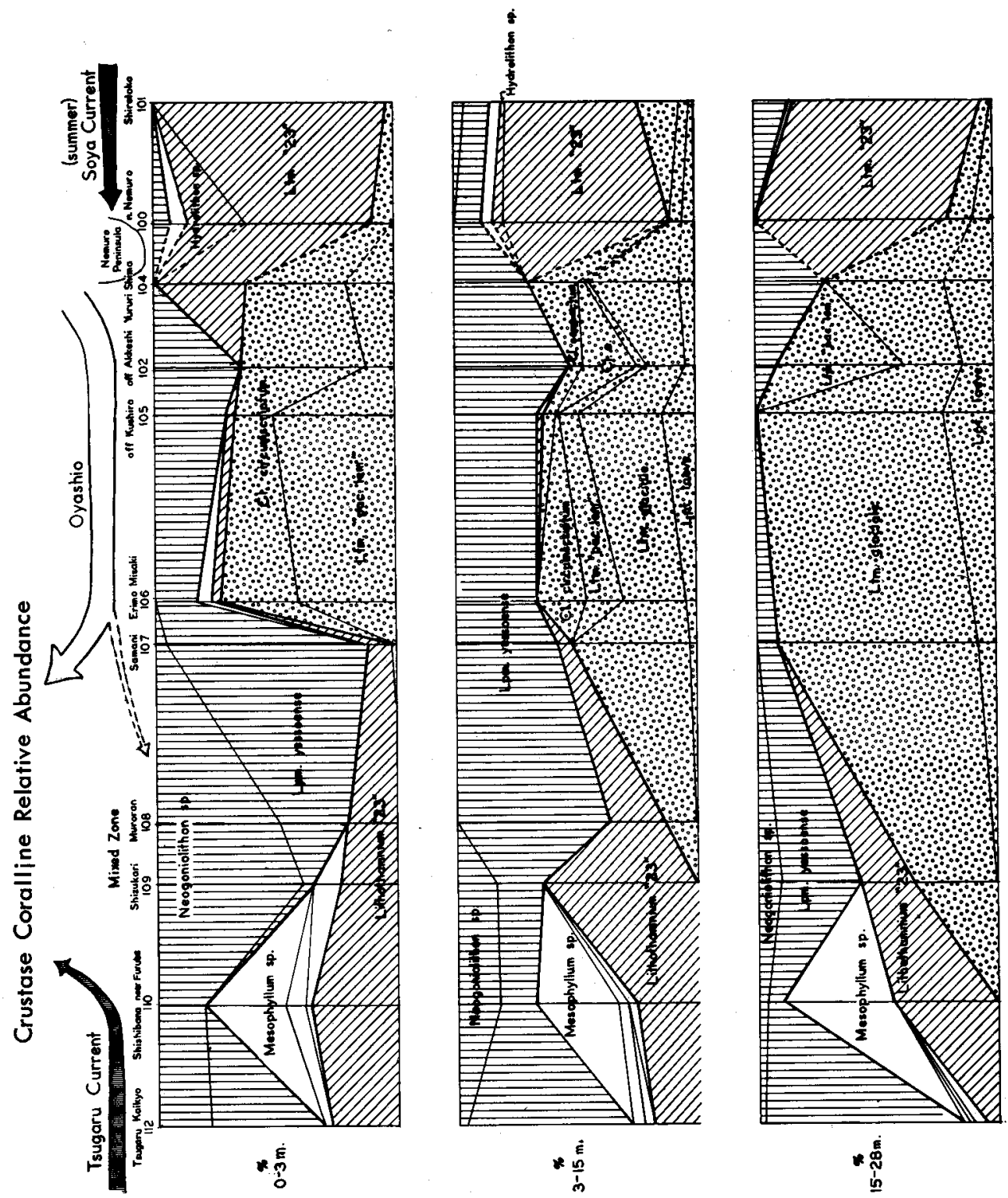

Fig. 4. Relative abundance (area coverage) of crustose coralline species in eastern and southern Hokkaido, as a function of geographic location, ocean currents and depth. , cold water species - subarctic; $\}$ warm water species - $\left\{\begin{array}{l}\text { cold temperate } \\ \text { warm temperate }\end{array}\right.$ $\square$, species of unknown biogeographic affinities. 
Bull. Fac. Fish. Hokkaido Univ. 26(4), 1976.

waters. Outside of the area under discussion, two species have been described from the warm temperate Mediterranean (Hamel and Lemoine ${ }^{12)}$ ), and two species from subtropical to warm temperate Pacific Mexico (Dawson, l.c., Lithophyllum trichotomum and Hydrolithon setchellii). A single species extends into temperate California (Mason,11) as Hydrolithon setchellii). Lithothamnium "23" also occurs in significant amounts in the Tsugaru to Erimo area, and as shown in figures 1 and 4 , this coast is a warm to cold temperate transition in shallow water and is a threeway transition (with some subarctic elements) in deep water.

In addition to the crustose coralline species mentioned above, several additional taxa were found in relatively small amounts in our collections. The biogeographic relationship of these are presently obscure. The most important of these "additional elements", Mesophyllum sp. is discussed below.

\section{Discussion}

There are five major species in the subarctic group on the eastern Hokkaido coast: Clathromorphum circumscriptum and Lithothamnium "pac-lem." in shallow zones; Clathromorphum compactum a little deeper; and Lithothamnium glaciale and Leptophytum laeve in the deepest areas. Four of these are also the principal elements of the subarctic flora of the North Atlantic; the fifth, Lithothamnium "pac-lem." is quite similar to the only coralline species endemic to the North Atlantic subarctic, Lithothamnium lemoineae, thus indicating a common ancestor.

Of the shallow elements, the dominant Clathromorphum circumscriptum and Lithothamnium "pac-lem." extend into the 9-15 meter depth range, but rarely occur over 15 meters. This is the same pattern of depth distribution exhibited by $C$. circumscriptum in the North Atlantic. L. lemoineae, the North Atlantic twin of $L$. "pac-lem." is also most abundant in shallow water (Adey ${ }^{13)}$ ). In both Hokkaido and the North Atlantic, C. circumscriptum often extends into intertidal pools while $L$. lemoineae and $L$. "pac-lem." rarely do. It has been demonstrated that in the North Atlantic, Clathromorphum circumscriptum is rather strictly limited by maximum temperatures of about $17-18^{\circ} \mathrm{C}$ and requires winter temperatures below about $2^{\circ} \mathrm{C}$ (Adey $\left.{ }^{14}\right)$ ). At the southern limit of its occurrence in shallow water in Hokkaido, just west of Cape Erimo, very similar temperature conditions are found.

In the North Atlantic, Clathromorphum compactum is primarily found at three to twenty meters depth, depending on turbidity. Below this, Lithothamnium glaciale is highly abundant in mid to deeper water, with Leptophytum laeve becoming increasingly abundant near the lower end of the photic zone. This is also the pattern of distribution for these three species in the Hokkaido subarctic.

The pan-subarctic group dominates the shallow zones from Nemuro Peninsula to Cape Erimo. In deeper water it penetrates further west, reaching at least to Muroran and Funka Bay, to the west of Muroran. On September 1, in a nontransect dive just north of Cape Esan (near Shishibana, sta. 110) a few Clathromorphum circumscriptum plants and abundant Lithothamnium glaciale were

$$
-310-
$$


found at 30 meters. The temperature at this depth was $9.7^{\circ} \mathrm{C}$, while the surface temperature was $21.9^{\circ} \mathrm{C}$. In this area, because of the influence of the clear Tsugaru surface water and the steep bottom profile, benthic algae probably extend in many places to 60-70 meters. Especially interesting is the probability that in some places a strong, warm temperate benthic flora overlies a dominantly subarctic one, separated by as little as five to fifteen meters in depth.

Ekman (l. c.) suggested that a major part of the North Atlantic fauna originated in the North Pacific. If the amount of coastline available under subarctic conditions has been a major factor determining the course of evolution of the shallow water subarctic biota, figure 1 clearly demonstrates why the North Pacific has played this dominant role. The North Pacific subarctic, with a coastal length over two and one half times greater than that of the subarctic North Atlantic, is concentrated in the Bering and Okhotsk Seas, where winter temperatures are 0 to $-1^{\circ} \mathrm{C}$ and summer temperatures are $8-12^{\circ} \mathrm{C}$. Such a concentration of coastline length largely results from the subduction of coastal plates which occurs extensively in the North Pacific, giving rise to much tectonic activity, related island arcs and secondary seas. This contrasts with the plate "rifting" occurring in the North Atlantic that results in stable shorelines and relatively few islands.

Ekman (l. c.) also suggests that there is some paleoecologic evidence in the mid to later Tertiary for somewhat higher temperatures in the North Atlantic than in the North Pacific, presumably resulting in an even smaller zone of subarctic (or developing subarctic) in the Atlantic. The alternate opening and closing of the Bering Land Bridge in the late Tertiary and Pleistocene (Hopkins ${ }^{15)}$ ) has generally acted to keep the two subarctic areas in contact over the time scale of coralline and invertebrate species evolution.

As discussed previously, we have separated the warm water coralline species into cold and warm components. Hydrolithon sp. and Lithothamnium "23" dominate in the Shiretoko-Nemuro bight and are considered of cold temperate derivation. Neogoniolithon sp. and Lithophyllum yessoense dominate in the southern and western parts of Hokkaido and probably derive from the North Pacific warm temperate zone as defined on figure 1.

At the theoretical center of the North Pacific cold temperate province in the northern Sea of Japan and Okhotsk Sea, the mean summer temperature is apparently $16-17^{\circ} \mathrm{C}$, which is almost a degree colder than that recorded at Cape Erimo, the southern limit of the subarctic province on the Hokkaido coast. Given this apparent overlap of the two provinces, it is puzzling that Lithothamnium " 23 ", the dominant species of the cold temperate group, does not extend further into the subarctic province in eastern Hokkaido. This could be an indication of incomplete temperature data. We suggest that in the subarctic province, on the outer coasts where our collections were taken, the temperatures are actually lower than the figures used to calculate the means used in figure 3 . Furthermore, in view of the limited temperature data available from the northern Sea of Japan and Sakhalin, it is also possible that nearshore information would show this area to be several degrees warmer than we have indicated. If this were the case, the 
Bull. Fac. Fish. Hokkaido Univ. 26(4), 1976.

postulated center of distribution for the north Pacific cold temperate flora would be more separated (at relatively higher summer temperatures) from the subarctic in figure 1.

Several additional coralline species were also found in small amounts at several stations. Presumably these are warm elements that will be better understood after further study in Honshu and the Sea of Japan. However, a single undescribed Mesophyllum species was the dominant plant at Shishibana, near Cape Esan, representing $30 \%$ of coralline coverage at all depths. In previous studies, relative abundances of coralline species have been found to be consistent from station to station along extended stretches of outer coast in temperate to arctic areas. Isolated occurrences in high abundance of single species not found elsewhere in the area have not been encountered before. Hopefully, further studies in the western Pacific will clarify this situation.

\section{Acknowledgments}

The fisheries cooperatives, their staffs and boats at Rausu, Nemuro, Akkeshi, Erimo, Samani and Toyoura provided invaluable assistance in occupying stations and working collections in those areas. Mr. Sasaki of the Fisheries Institute in Kushiro helped to arrange our study at many fisheries cooperatives and provided much assistance in our work near Kushiro. In the Akkeshi area, we were able to use the boats of the marine lab, even though the lab itself was partly under reconstruction, and at Muroran, Professor Nakamura most generously provided to us the facilities of the marine station. While in the Oshima area we worked from the Hokkaido University Faculty of Fisheries marine station at Usujiri and at the phycological laboratories in Hakodate. The Faculty of Fisheries research vessel "Ushio Maru" allowed us to quickly accomplish stations, with deep dredgings in eastern Oshima and the Tsugaru Strait.

P. Adey served as a diving partner at all stations. She was also responsible for a major part of the collection processing and provided considerable editorial and technical assistance. Most of the drawings were done by B. Larson.

\section{Summary}

Based on a series of depth-zoned collections taken by SCUBA, the relative abundances of species of crustose coralline algae along the eastern and southern coasts of Hokkaido were examined with regard to the major ocean currents and the resulting temperature patterns.

Three geographic groupings of species were found: (a) a cold water group strongly dominating along the east coast from Cape Erimo to Cape Nosappu; (b) a warmer water group occurring in the northeast from Cape Nosappu to Cape Shiretoko; and (c) a third, warm water group occurring in the Tsugaru Strait. The coast from Cape Erimo to Tsugaru Strait is occupied by a transitional complex of species.

Based on a graphic study of the amount of contiguous coastline in the northern hemisphere occurring at various combinations of summer and winter surface water 
ADEY et al.: Crustose corallines in eastern Hokkaido

temperatures, a physical basis for the delimitation of shallow water coastal biogeographic provinces is derived. The close correlation of these patterns with the actual geographic distribution of crustose corallines in this study, and in those previously undertaken in the North Atlantic, is discussed.

The cold water species are shown to be the southernmost extension in the Pacific of the broad subarctic group, most of the species present in Hokkaido also occurring in the North Atlantic. The basis for the North Pacific origin of the subarctic flora is also discussed. The two warm water groups are referred to as cold temperate (northeast Hokkaido) and warm temperate (Tsugaru Strait), and it is postulated that the centers of distribution of these provinces are respectively in the southern Okhotsk and northern Sea of Japan, and the southern Sea of Japan to East China Sea area.

\section{References}

1) Adey, W.H. and P.J. Adey. (1973). Studies on the biosystematics and ecology of the epilithic crustose Corallinaceae of the British Isles. Br. phycol. J. 8, 343-407.

2) Masaki, T. (1968). Studies on the Melobesioideae of Japan. Mem. Fac. Fish. Hokkaido Univ. 16, 1-80.

3) Masa,ki, T., H. Akioka and W.H. Adey. A biosystematic study of the crustose corallines of Hokkaido (in prep.).

4) Hedgepeth, J. (1957). Marine biogeography. In, Treatise on marine ecology and paleoecology. Geol. Soc. Am. Mem. 67, 1296p.

5) Ekman, S. (1967). Zoogeography of the Sea. 417p. London.

6) Rotramel, G. (1973) The development of the area concept in biogeography. Syst. Zool. 22, 227-232.

7) Stehli, F. and J.W. Wells. (1971). Diversity and age patterns in hermatypic corals. Syst. Zool. 20, 115-126.

8) Adey, W.H. (1971). The sublittoral distribution of crustose corallines on the Norwegian Coast. Sarsia. 46, 41-58.

9) Adey, W.H. (1970). A revision of the Foslie crustose coralline herbarium. $K$. Norske Vid. Selsk. Skr. 1970. 1-46.

10) Dawson, E.Y. (1960). Marine red algae of Pacific Mexico, Part 3. Pacific Naturalist. 2, 1-125.

11) Mason, L.R. (1953). The crustaceous coralline algae of the Pacific coast of the United States, Canada and Alaska. Univ. Calif. Publ. Bot. 26, 313-390.

12) Hamel, G. and M. Lemoine. (1952). Corallinacees de France et d'Afrique du Nord. Arch. Mus. Nat. d'Hist. Nat., ser. 7, 1, 16-136.

13) Adey, W.H. (1966). Distribution of saxicolous crustose corallines in the northwestern North Atlantic. J. Phycol. 2, 49-54.

14) Adey, W.H. (1973). Temperature control of reproduction and productivity in a subarctic coralline alga. Phycologia. 12, 111-118.

15) Hopkins, D.M. (1967). The Bering Land Bridge. 495p. Stanford. 